\title{
The Senile Lung as a Possible Source of Pitfalls on Chest Ultrasonography and Computed Tomography
}

\author{
Federica Ciccarese $^{a}$ Anna Maria Chiesa ${ }^{a}$ Francesco Felettic ${ }^{c}$ Luca Vizioli $^{b}$ \\ Milena Pasquali ${ }^{a}$ Paola Forti ${ }^{b}$ Marco Zoli ${ }^{b}$ Maurizio Zompatoria \\ ${ }^{a}$ Radiology Unit, Cardiothoracic-Vascular Department, and bepartment of Medical and Surgical Sciences, S. Orsola-

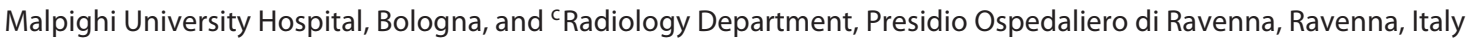

\section{Key Words}

Aging lung $\cdot$ Ultrasonography $\cdot$ Chest computed tomography

\begin{abstract}
Background: Age-associated changes in the pulmonary system could be detected with imaging techniques. Widespread use of lung ultrasonography (US) requires characterization of a normal pattern. Objectives: To compare US and computed tomography (CT) findings in healthy subjects undergoing both techniques (with CT as the gold standard). Methods: We prospectively selected 59 subjects undergoing chest CT and US on the same day, without a history of smoking, respiratory symptoms, or known pulmonary pathologies. There were 44 patients in group 1 (age $\geq 60$ years - elderly) and 15 patients in group 2 (age $\leq 50$ years young). Lung US was performed with a convex and a linear probe, and 10 chest areas per patient were analyzed. Convex and linear probe agreement was evaluated by means of the Cohen K statistic; Fisher's exact test was used to compare categorical variables between groups. Results: Isolated Blines were frequent in both group 1 (54.5\%) and group 2 (40.0\%); the number of chest areas positive for B-lines increased with age $(16.1 \%$ in group 1 vs. $5.3 \%$ in group $2, p=$
\end{abstract}

0.0028). In group 2, we found that $37.5 \%$ of subjects with Blines had at least 1 chest area with multiple B-lines, but only 2 subjects had 2 or more. Moreover, in group 1 the chest CT documented a reticular pattern $(2.3 \%)$, areas of increased density $(9.1 \%)$, ground glass $(6.8 \%)$, cysts $(2.3 \%)$, bronchiectasis $(22.7 \%)$, and bronchial thickening (6.8\%); in group 2, only cysts $(6.7 \%)$ and bronchiectasis $(6.7 \%)$ were found. Conclusions: The senile lung is characterized by mild changes on CT and US. Chest areas positive for B-lines increase with age, and focal multiple B-lines can be found. However, diffuse patterns, especially in symptomatic subjects, suggest a different diagnosis.

(c) 2015 S. Karger AG, Basel

\section{Purpose}

There are many age-associated changes in the respiratory and pulmonary system. Changes in the spine, muscles and ribs negatively impact normal lung function [1]; moreover, the reduced cough strength, in addition to mucociliary dysfunction and alterations in the immunity system, leads to an increase susceptibility to infections [2].

Histopathological studies have demonstrated that modifications in extracellular matrix might contribute to

\section{KARGER 125}

(c) 2015 S. Karger AG, Base

0025-7931/15/0901-0056\$39.50/0

E-Mail karger@karger.com

www.karger.com/res
Federica Ciccarese

Radiology Unit, Cardiothoracic-Vascular Department

S. Orsola-Malpighi University Hospital, Via Massarenti 9

IT-40100 Bologna (Italy)

E-Mail ciccarese.f@gmail.com 
the physiological decline in lung function; essentially, fibronectin expression increases with excessive deposition of collagen proteins, whereas the content of elastin fibers is decreased; the result is an enlargement of the distal airspace and abnormal tissue remodeling [3].

Radiological techniques are able to detect such changes, showing several differences among young and elderly subjects; recent studies on computed tomography (CT) revealed that a subpleural reticular pattern could be observed in $60 \%$ of healthy individuals older than 75 years [4].

The use of lung ultrasonography (US) has recently been spreading in several fields, especially in the intensive care unit (ICU) and in the emergency setting $[5,6]$. However, there is a lack of a definition for age-related changes in the normal US pattern (except for one study), which could be essential to better target the diagnosis [7].

Thus, our aim was to compare US findings in healthy elderly and young subjects undergoing chest CT, considered as the gold standard.

\section{Materials and Methods}

From January 2013 to January 2014, we prospectively selected 59 patients undergoing lung US on the same day as a chest CT scan, with the approval of our Institutional Review Board.

The inclusion criteria were: absence of a history of smoking, respiratory symptoms, known pulmonary pathologies, and clinically relevant cardiac diseases (i.e. left heart failure). Informed consent was obtained from all recruited individuals. If the CT scan showed parenchymal consolidations, extensive ground-glass opacities, pleural effusion, fibro-/pneumothorax, pleural plaques, tree in bud, bronchiectasis, emphysema, pulmonary fibrosis, an extensive nodular pattern, or outcomes of thoracic surgery, the patient was excluded.

Chest CT was performed for indications completely independent of our study (control of pulmonary nodules, follow-up of extrathoracic tumors, suspected connective tissue diseases, pulmonary hypertension, pretransplant evaluation, professional exposure).

Two expert observers, blinded to each other, analyzed the CT and US exams.

\section{CT Technique}

All CT were performed using a 16-detector row CT system (Somatom Sensation 16; Siemens Medical Solutions, Forchheim, Germany) during one deep inspiratory breath-hold with or without the use of contrast medium; the standard parameters were as follows: $120 \mathrm{kV}, 120 \mathrm{mAs}$, and 0.75 collimation. The reconstructed data for the detection of pulmonary nodules (2-mm-thick sections with a reconstruction increment of $1 \mathrm{~mm}$ and a sharp kernel, i.e. Siemens B80 kernel) were considered for our study. All CT scans were performed with the patient in supine decubitus; if an interstitial lung disease was suspected, an extra scan with the patient in prone decubitus was also obtained (in $21 / 59$ patients; $35.6 \%$ ).

The Senile Lung Pattern on US and CT
For each scan, we recorded: the presence of reticulations, areas of increased density, cysts, ground-glass opacities, the bronchoarterial ratio, bronchial wall thickness, and other findings. The bronchoarterial ratio was evaluated at the right apical and right posterior basal segments; these sites were chosen because they have been previously demonstrated to be more convenient for obtaining a tangential view of the bronchus and artery; only the right lung was evaluated because no difference exists between the right and left lungs in terms of the bronchoarterial ratio or wall thickening. Bronchiectasis was diagnosed when the bronchoarterial ratio was $>1[8]$.

\section{US Technique}

Lung US examinations were performed using commercially available echographic equipment (Technos; Esaote, Genova, Italy). Both a linear (5-8 MHz) and a convex (2-5 MHz) probe were used for the analysis, with the convex probe considered as the reference standard.

Ten chest areas were analyzed per patient, i.e. 5 per side: 4 chest areas per side with the patient in supine decubitus (upper and lower anterior chest area; upper and basal lateral chest area), referring to the criteria proposed for the detection of alveolar-interstitial syndrome [5, 9], and an extra scan per side for the analysis of the posterobasal chest area with the patient in a seated position. The presence, site and number of B-lines were recorded.

B-lines were defined as a hyperechoic and well-defined comet tail artifact arising from the pleural line, spreading up to the edge of the screen, erasing A-lines and moving with lung sliding [10]. A chest area was considered positive when $\geq 3 \mathrm{~B}$-lines were found [5].

\section{Statistical Analysis}

Patients were divided into the following 2 groups by age: group 1 (age $\geq 60$ years - elderly) and group 2 (age $\leq 50$ years - young). We did not include patients between the ages of 50 and 60 because we wanted to consider 2 groups of subjects with different ages, as previously done by other authors $[4,7]$. Continuous variables are reported as means \pm SD and categorical data as numbers (\%). Fisher's exact test was used to compare categorical variables between groups; $\mathrm{p}<0.05$ was considered statistically significant.

Convex and linear probe agreement was evaluated by means of the Cohen $\kappa$ statistic; excellent agreement was defined by $\kappa>0.75$.

\section{Results}

Group 1 included 44 subjects (25 females and 19 males), with a mean age of $72.6 \pm 7.3$ years; group 2 included 15 subjects ( 8 females and 7 males), with a mean age of $43.0 \pm 9.3$ years.

On lung US, among a total of 590 chest areas scanned (i.e. 440 for group 1 and 150 for group 2), no pathological findings were detected, except for the presence of B-lines.

The prevalence of B-lines did not differ by age and was highly frequent, occurring in up to $50 \%$ of subjects. However, the number of chest areas with B-lines was significantly higher in group 1 compared to group 2 (table 1 ). 
Fig. 1. Multiple B-lines ( $\geq 3$ ) detected in a 94-year-old male with both a convex (a) and a linear probe (b).

Table 1. B-line detection by age group
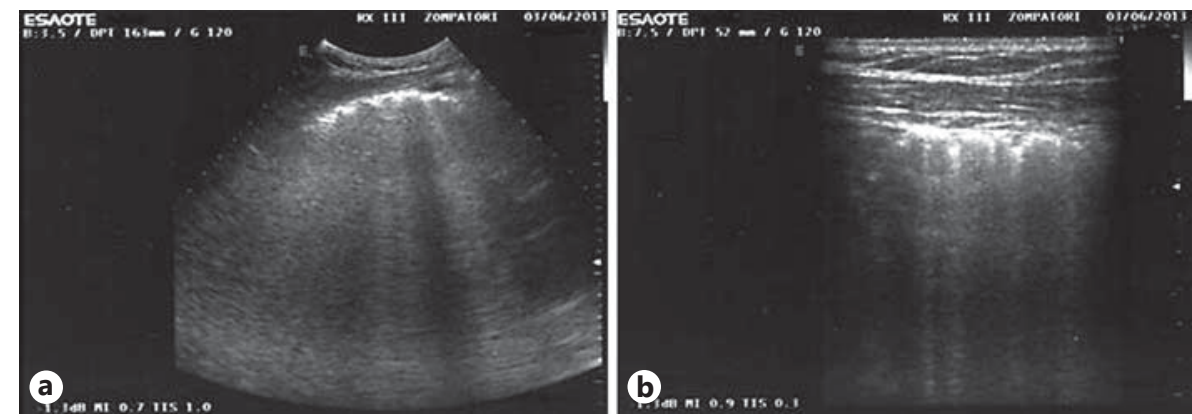

\begin{tabular}{llll}
\hline & Group 1 & Group 2 & p \\
\hline Subjects positive for B-lines & $24 / 44(54.5 \%)$ & $6 / 15(40.0 \%)$ & 0.250 \\
Chest areas positive for B-lines & $71 / 440(16.1 \%)$ & $8 / 150(5.3 \%)$ & 0.0028 \\
\hline
\end{tabular}

Table 2. B-line distribution among the 10 chest areas analyzed

\begin{tabular}{lc}
\hline Chest areas with B-lines (any number) & Patients $(\mathrm{n}=59)$ \\
\hline Right basal lateral & $17(28.7)$ \\
Left basal lateral & $14(23.7)$ \\
Right posterobasal & $12(20.3)$ \\
Right upper anterior & $9(15.2)$ \\
Left posterobasal & $9(15.2)$ \\
Right upper lateral & $6(10.1)$ \\
Right lower anterior & $5(8.5)$ \\
Left upper anterior & $4(6.8)$ \\
Left upper lateral & $3(5.0)$ \\
Left lower anterior & $1(1.7)$ \\
\hline
\end{tabular}

Values are presented as numbers (\%).

Table 3. Multiple B-line distribution ( $\geq 3$ ) among the 10 chest areas analyzed

\begin{tabular}{ll}
\hline Chest areas with multiple B-lines $(\geq 3)$ & Patients $(\mathrm{n}=59)$ \\
\hline Left posterobasal & $4(6.8)$ \\
Right posterobasal & $3(5.0)$ \\
Left basal lateral & $3(5.0)$ \\
Right basal lateral & $3(5.0)$ \\
Right lower anterior & $2(3.4)$ \\
Right upper lateral & $2(3.4)$ \\
Right upper anterior & $1(1.7)$ \\
Left upper anterior & $1(1.7)$ \\
Left lower anterior & $1(1.7)$ \\
Left upper lateral & $1(1.7)$ \\
\hline
\end{tabular}

Values are presented as numbers (\%).
Moreover, 9 out of the 24 subjects with B-lines in group $1(37.5 \%)$ had at least 1 chest area with multiple B-lines (vs. only 1 patient in group 2; fig. 1). Among them, 2 subjects showed more than 1 area with multiple B-lines; they were a 77 -year-old male ( 2 areas) and a 94-year-old male (10 areas); the CT scan was negative for pathological findings in the first patient and documented only diffuse bronchial wall thickening in the second patient.

The distribution of B-lines, whether isolated or multiple, is shown in tables 2 and 3 . The results from the convex and linear probes had excellent agreement $(\kappa=0.83)$.

None of the CT findings detected reached statistical significance due the small number of positive findings in group 2; a detail report is shown in table 4 .

\section{Discussion}

Apart from the physiological changes that occur with age, certain pathological conditions, such as idiopathic pulmonary fibrosis and chronic obstructive pulmonary disease, are more frequently related to pulmonary senescence. A recent hypothesis suggested that these two entities share common pathogenetic mechanisms of accelerated senescence via telomere length abnormalities [11]; moreover, we must consider that the life expectancy has gone up, thus allowing more time for a chronic indolent progressive disease to manifest itself [12]. Not surprisingly, cases of simultaneous emphysema and pulmonary fibrosis have been finally described and proposed as a distinct entity termed combined pulmonary fibrosis and emphysema $[13,14]$. 
Table 4. CT findings by age group

\begin{tabular}{lcl}
\hline & $\begin{array}{c}\text { Group 1 } \\
(\mathrm{n}=44)\end{array}$ & $\begin{array}{l}\text { Group 2 } \\
(\mathrm{n}=15)\end{array}$ \\
\hline Reticular pattern & $1(2.3)$ & 0 \\
Areas of increased density & $4(9.1)$ & 0 \\
Ground-glass opacities & $3(6.8)$ & 0 \\
Cysts & $1(2.3)$ & $1(6.7)$ \\
Bronchiectasis & $10(22.7)$ & $1(6.7)$ \\
Bronchial wall thickness & $3(6.8)$ & 0 \\
\hline
\end{tabular}

Values are presented as numbers (\%).

In the elderly, chest X-rays often show unspecific abnormalities mainly consisting of hyperinflation and increased markings [15].

The advent of CT has provided greater anatomical detail, allowing the identification of signs of aging. As previously observed, an increased bronchial wall thickness and bronchoarterial ratio are more frequently detected, with up to $40 \%$ of subjects older than 65 years overlapping with the ratio considered to represent bronchiectasis $[8,16]$; the frequency of air trapping increases [17]; basal fibrotic reticulations are a common finding [4]; the lung structure becomes less complex, probably due to the progressive decrease in vascular structures and to alveolar dilatation [18].

In such a contest, age-related changes may be difficult to differentiate from the early stages of chronic obstructive pulmonary disease or idiopathic pulmonary fibrosis. Although there are no normative values described in literature, age-related changes are described to be moderate; extensive modifications, in addition to other signs such as marked honeycombing, traction bronchiectasis and ground-glass opacities, are all in favor of a pathological pattern [19].

Nowadays, there is great interest in the application of lung US in the ICU. The main advantages of lung US consist of delaying or even avoiding transportation to the radiology unit (also preventing radiation exposure) and integration of the low information content provided by bedside radiography [20]. Moreover, sonographic study of the lung can be performed with any modern US unit; the device can be obtained with the use of simple technology, with neither Doppler nor complex modes (i.e. harmonics), allowing immediate use and a low cost [21]; both a linear and a convex probe could be used, though a sector probe is preferred in the critical setting to also integrate data from echocardiography $[22,23]$.

The Senile Lung Pattern on US and CT
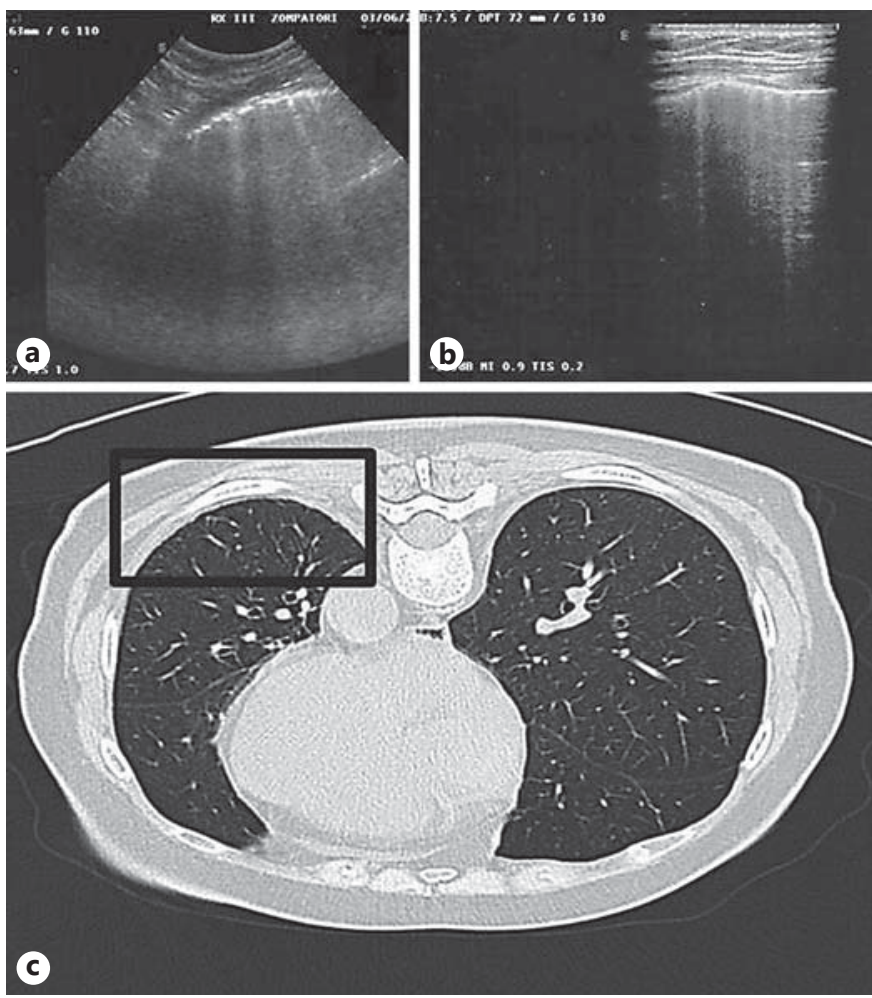

Fig. 2. Seventy-three-year-old female with multiple B-lines (a, b) detected on a left posterobasal scan. The CT scan (c) in prone decubitus did not show pathological findings.

The identification of B-lines represents a cornerstone for the diagnosis of interstitial syndrome, which includes pulmonary edema of various causes, interstitial pneumonia, pulmonary fibrosis and acute respiratory distress syndrome [5]. The generation of B-lines is still unclear, but it is supposed to be the sonographic expression of increased lung density; the latest hypothesis suggests that B-lines could be produced when the ultrasound beam can see, in relation to its wavelength, a nonimpeding structure (a sort of microhole), which can allow it to infiltrate highly reflective surfaces that can provoke complex acoustic events (focal reverberations modified by eventual interferences) read by the ultrasound machine with artifact formation [24]. Traditionally, B-lines have been attributed to thickening of the subpleural connective tissue (increased extravascular content or tissue content), as occurs in the pathologic lung. However, a recent paper by Soldati et al. [25] demonstrated that B-lines and white lung can also be obtained by reducing the volume of a healthy lung. Thus, the pathogenesis of B-lines involves not only the air/water/tissue ratio but also the porosity of 


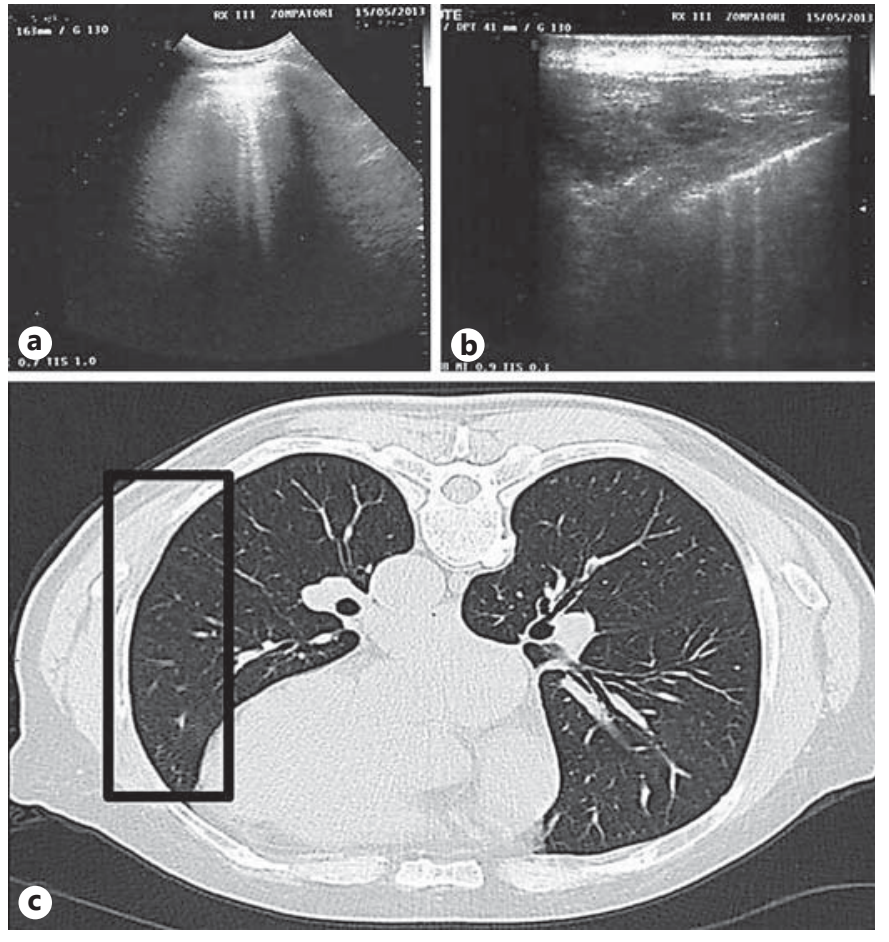

Fig. 3. Sixty-three-year-old female with $2 \mathrm{~B}$-lines detected on a left basal lateral scan $(\mathbf{a}, \mathbf{b})$ and absence of pathological signs on CT (c).

the lungs in terms of shape and disposition of air (peripheral airspace geometry).

An abnormal sonographic scan is defined by 3 or more $\mathrm{B}$-lines, and the diagnosis of acute interstitial syndrome requires at least 2 positive scans per side [9]; in these patients, the assessment of B-lines could represent a simple and semiquantitative method to measure interstitial-alveolar imbibition (i.e. as an index of extravascular lung water) [26].

More recently, lung US has been proposed as a feasible screening tool for interstitial lung disease in patients with a connective tissue pathology, such as rheumatoid arthritis or systemic sclerosis; indeed, the detection of B-lines strongly correlates with signs of interstitial lung disease on high-resolution CT scan $[27,28]$.

Previous studies have also documented B-lines in normal lung; isolated B-lines could be observed in healthy subjects (mean: 1.9 per scan) [29], as could positive scans for multiple B-lines, mainly confined to laterobasal areas

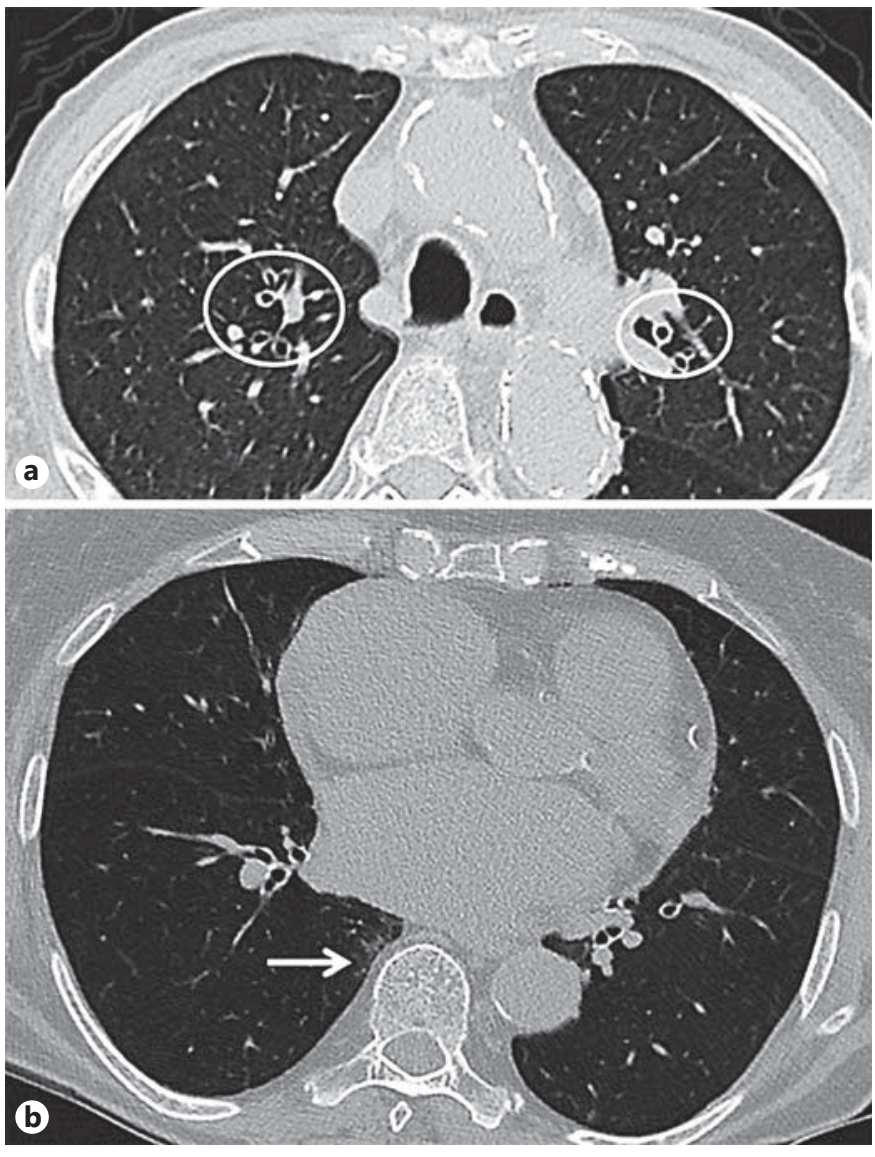

Fig. 4. Signs of aging detected on chest CT. Bronchial thickening (a) and an area of increased density next to the spine (b).

[30], and they are far from uncommon among the elderly [7].

Taken together, our data suggests that B-lines can be commonly found in healthy subjects ( $40-50 \%$ of cases in our series) but are mainly isolated. However, the number of chest areas positive for B-lines increases with age; up to $40 \%$ of healthy elderly patients with B-lines present at least 1 positive scan for multiple B-lines, but they rarely fulfill the criteria for the diagnosis of interstitial syndrome (only 1 patient). Focal multiple B-lines commonly coexist with other pathological conditions, such as pneumonia, atelectasis, pulmonary contusion, pulmonary infarction, pleural disease and neoplasia [5]. However, in our series they were not associated with any pathological finding, as demonstrated on the CT scan (fig. 2, 3). The kind of probe used did not influence the results. We suppose that the increased detection of B-lines depends on the physiological process of aging and is probably linked to changes in extracellular matrix or in peripheral airspace geometry. 
Based on the analysis of the CT data, we confirm that healthy elderly could commonly present areas of increased density (mainly in the posterobasal regions), bronchiectasis and bronchial wall thickening (fig. 4). Contrary to what was reported by Copley et al. [4], we did not find reticular changes, except in 1 patient. This discrepancy could be explained by the method of patient selection: first, we considered only never-smoking patients; second, the previous study enrolled subjects older than 75 years, whereas we considered a slightly younger population; third, we excluded patients with a moderate/extensive fibrotic pattern, as our main aim was to select a normal population to compare US findings and their changes according to age. Nevertheless, there might have been a selection bias. Our subjects did not show respiratory symptoms or pulmonary pathologies, but they were not truly representative of the healthy population as they were undergoing a clinically indicated chest CT scan; moreover, spirometric data were not available.
However, this is the first prospective study to compare US findings in healthy, never-smoking individuals to those of CT, which is the gold standard technique in pulmonary pathologies. In addition, US examinations were performed with two different probes (linear and convex) with a concordance of results.

In conclusion, our data suggest that lung US is able to detect signs of aging as well as CT does. The number of B-lines increases and focal multiple B-lines could be detected in any chest area. As the life expectancy is increasing and the use of lung US is spreading, this data should be taken into consideration in daily practice in order to avoid misdiagnoses. The border between normality and pathology has always been a topic of debate, especially with aging. However, the senile lung is characterized by mild and focal changes.

Thus, in cases of a diffuse and extensive pattern, usually found in symptomatic subjects and in the ICU, other diagnoses are more likely than senile lung, without doubts regarding a differential diagnosis.

\section{References}

1 Janssens JP, Pache JC, Nicod LP: Physiological changes in respiratory function associated with ageing. Eur Respir J 1999;13:197-205.

-2 Lowery EM, Brubaker AL, Kuhlmann E, Kovacs EJ: The aging lung. Clin Interv Aging 2013;8:1489-1496.

3 Kapetanaki MG, Mora AL, Rojas M: Influence of age on wound healing and fibrosis. J Pathol 2013;229:310-322.

-4 Copley SJ, Wells AU, Hawtin KE, Gibson DJ, Hodson JM, Jacques AE, Hansell DM: Lung morphology in the elderly: comparative CT study of subjects over 75 years old versus those under 55 years old. Radiology 2009;251: 566-573.

5 Volpicelli G, Elbarbary M, Blaivas M, Lichtenstein DA, Mathis G, Kirkpatrick AW, Melniker L, Gargani L, Noble VE, Via G, Dean A, Tsung JW, Soldati G, Copetti R, Bouhemad B, Reissig A, Agricola E, Rouby JJ, Arbelot C, Liteplo A, Sargsyan A, Silva F, Hoppmann R, Breitkreutz R, Seibel A, Neri L, Storti E, Petrovic $\mathrm{T}$; International Liaison Committee on Lung Ultrasound (ILC-LUS) for International Consensus Conference on Lung Ultrasound (ICC-LUS): International evidence-based recommendations for point-of-care lung ultrasound. Intensive Care Med 2012;38:577-591.

6 Kreuter M, Mathis G: Emergency ultrasound of the chest. Respiration 2014;87:89-97.

-7 Chiesa AM, Ciccarese F, Gardelli G, Regina UM, Feletti F, Bacchi Reggiani ML, Zompatori M: Sonography of the normal lung: compari- son between young and elderly subjects. J Clin Ultrasound 2014, DOI: 10.1002/jcu.22225.

8 Matsuoka S, Uchiyama K, Shima H, Ueno N, Oish S, Nojiri Y: Bronchoarterial ratio and bronchial wall thickness on high-resolution CT in asymptomatic subjects: correlation with age and smoking. AJR Am J Roentgenol 2003;180:513-518.

-9 Volpicelli G, Mussa A, Garofalo G, Cardinale L, Casoli G, Perotto F, Fava C, Frascisco M: Bedside lung ultrasound in the assessment of alveolar-interstitial syndrome. Am J Emerg Med 2006;24:689-696.

10 Lichtenstein DA, Mezière GA: Relevance of lung ultrasound in the diagnosis of acute respiratory failure: the BLUE protocol. Chest 2008;134:117-125.

11 Chilosi M, Carloni A, Rossi A, Poletti V: Premature lung aging and cellular senescence in the pathogenesis of idiopathic pulmonary fibrosis and COPD/emphysema. Transl Res 2013;162:156-173.

12 Cosio MG, Cazzuffi R, Saetta M: Is chronic obstructive pulmonary disease a disease of ag ing? Respiration 2014;87:508-512.

13 Cottin V, Nunes H, Brillet PY, Delaval P, Devouassoux $\mathrm{G}$, Tillie-Leblond I, Israel-Biet $\mathrm{D}$, Court-Fortune I, Valeyre D, Cordier JF; Groupe d'Etude et de Recherche sur les Maladies Orphelines Pulmonaires (GERM O P): Combined pulmonary fibrosis and emphysema: a distinct underrecognised entity. Eur Respir J 2005;26:586-593.
14 Travis WD, Costabel U, Hansell DM, King TE Jr, Lynch DA, Nicholson AG, Ryerson CJ, Ryu JH, Selman M, Wells AU, Behr J, Bouros D, Brown KK, Colby TV, Collard HR, Cordeiro CR, Cottin V, Crestani B, Drent M, Dudden RF, Egan J, Flaherty K, Hogaboam C, Inoue Y, Johkoh T, Kim DS, Kitaichi M, Loyd J, Martinez FJ, Myers J, Protzko S, Raghu G, Richeldi L, Sverzellati N, Swigris J, Valeyre D; ATS/ ERS Committee on Idiopathic Interstitial Pneumonias: An official American Thoracic Society/European Respiratory Society statement: update of the international multidisciplinary classification of the idiopathic interstitial pneumonias. Am J Respir Crit Care Med 2013;188:733-748.

15 Ensor RE, Fleg JL, Kim YC, de Leon EF, Goldman SM: Longitudinal chest X-ray changes in normal men. J Gerontol 1983;38:307-314.

16 Hansell DM: Thin-section CT of the lungs: the Hinterland of normal. Radiology 2010; 256:695-711.

17 Lee KW, Chung SY, Yang I, Lee Y, Ko EY, Park MJ: Correlation of aging and smoking with air trapping at thin-section CT of the lung in asymptomatic subjects. Radiology 2000;214:831-836.

$>18$ Copley SJ, Giannarou S, Schmid VJ, Hansell DM, Wells AU, Yang GZ: Effect of aging on lung structure in vivo: assessment with densitometric and fractal analysis of high-resolution computed tomography data. J Thorac Imaging 2012;27:366-371. 
19 Gossner J, Nau R: Geriatric chest imaging: when and how to image the elderly lung, agerelated changes, and common pathologies. Radiol Res Pract 2013;2013:584793.

20 Lichtenstein DA: Lung ultrasound in the critically ill. Ann Intensive Care 2014;4:1.

21 Lichtenstein D: Lung ultrasound in acute respiratory failure an introduction to the BLUEprotocol. Minerva Anestesiol 2009;75:313317.

22 Stefanidis K, Dimopoulos S, Nanas S: Basic principles and current applications of lung ultrasonography in the intensive care unit. Respirology 2011;16:249-256.

-23 Zanforlin A, Giannuzzi R, Nardini S, Testa A, Soldati G, Copetti R, Marchetti G, Valente S, Inchingolo R, Smargiassi A: The role of chest ultrasonography in the management of respiratory diseases: document I. Multidiscip Respir Med 2013;8:54.
24 Smargiassi A, Inchingolo R, Soldati G, Copetti R, Marchetti G, Zanforlin A, Giannuzzi R, Testa A, Nardini S, Valente S: The role of chest ultrasonography in the management of respiratory diseases: document II. Multidiscip Respir Med 2013;8:55.

25 Soldati G, Smargiassi A, Inchingolo R, Sher S, Nenna R, Valente S, Inchingolo CD, Corbo GM: Lung ultrasonography may provide an indirect estimation of lung porosity and airspace geometry. Respiration 2014;88:458468.

26 Jambrik Z, Monti S, Coppola V, Agricola E, Mottola G, Miniati M, Picano E: Usefulness of ultrasound lung comets as a nonradiologic sign of extravascular lung water. Am J Cardiol 2004;93:1265-1270.

27 Cogliati C, Antivalle M, Torzillo D, Birocchi S, Norsa A, Bianco R, Costantino G, Ditto MC, Battellino M, Sarzi Puttini PC, Montano $\mathrm{N}$ : Standard and pocket-size lung ultrasound devices can detect interstitial lung disease in rheumatoid arthritis patients. Rheumatology (Oxford) 2014;53:1497-1503.
28 Barskova T, Gargani L, Guiducci S, Randone SB, Bruni C, Carnesecchi G, Conforti ML, Porta F, Pignone A, Caramella D, Picano E, Cerinic MM: Lung ultrasound for the screening of interstitial lung disease in very early systemic sclerosis. Ann Rheum Dis 2013;72:390395.

29 Sperandeo M, Varriale A, Sperandeo G, Polverino E, Feragalli B, Piattelli ML, Maggi MM, Palmieri VO, Terracciano F, De Sio I, Villella M, Copetti M, Pellegrini F, Vendemiale G, Cipriani C: Assessment of ultrasound acoustic artifacts in patients with acute dyspnea: a multicenter study. Acta Radiol 2012;53:885892.

30 Volpicelli G, Caramello V, Cardinale L, Mussa A, Bar F, Frascisco MF: Detection of sonographic B-lines in patients with normal lung or radiographic alveolar consolidation. Med Sci Monit 2008;14:CR122-CR128. 